\title{
A Conjoint Analysis of Consumer Preferences for Traditional Cheeses in Turkey : A Case Study on Tulum Cheese
}

\author{
Hakan Adanacioglu* and Zubeyde Albayram \\ Department of Agricultural Economics, Faculty of Agriculture, Ege University, Bornova-Izmir 35100, Turkey
}

\begin{abstract}
In this study, consumer preferences toward traditional cheeses were investigated with Tulum cheese sample which is one of the traditional cheeses of Turkey. Type of milk used for Tulum cheese making was identified as the most important factor, followed by Tulum cheese's texture, price, salinity, fat content, origin and flavour. The ideal Tulum cheese profile for the overall consumers was made with cow milk, a hard texture, a price of $20 \mathrm{TL}$ per kg, a low salt cheese, a full fat cheese, the regional cheese which belongs to Izmir region and a mild-flavoured cheese.A cluster analysis revealed there were two clusters with different ideal product profiles. Cluster 1's ideal Tulum cheese comprised a soft texture, a mild-flavoured cheese, a cheese made with cow milk, a full fat cheese, a low salt cheese, the regional cheese which belongs to Izmir region and a price of $10 \mathrm{TL}$ per $\mathrm{kg}$. Cluster 2 differed from cluster 1 in that its ideal Tulum cheese was a hard textured cheese and priced at $20 \mathrm{TL}$ per kg. The consumers in cluster 2 were less price sensitive than those in cluster 1. In addition to, the consumers in both segments are ready to pay extra money for regional Tulum cheese versus non-regional Tulum cheese. We found that the older ones were more willing to pay as compared to younger individuals. Young people are critical target consumers for Tulum cheese marketers. The findings on cluster 1's ideal Tulum cheese of this study could therefore provide guidance to marketing managers.
\end{abstract}

Key wors: traditional cheeses, consumer preferences, conjoint analysis, Turkey

\section{Introduction}

Within Europe, there are many different cultures, each with their own, often distinctive, dietary traditions. Traditional foods include foods that have been consumed locally or regionally for many generations. Traditional foods are often considered healthy and wholesome and, as public interest in nutrition and healthy eating has increased, there has also been an increase in demand for traditional foods (Anonymous, 2007).

Traditional consumption structures are observed to change with the entrance of foreign brands and products into the market. Yet, the protection of traditional foods as one of the most important elements of cultural heritage, and efforts to spread the consumption of these foods increases as well.

However, there is little information about the preferences of consumers toward the traditional foods in many countries. Turkey is one of these countries. In Turkey, in

*Corresponding author: Hakan Adanacioglu, Department of Agricultural Economics, Ege University, Bornova-Izmir 35100, Turkey, Tel: 90-23-2388-1862; Fax: 90-23-2388-1864, E-mail: hakan. adanacioglu@ege.edu.tr order to reduce the risk and uncertainty on the market, it is necessary for traditional food producers or marketers to assess consumer behavior (Albayrak and Gunes, 2010). In this study, consumer preferences towards traditional foods were investigated with Tulum cheese sample which is one of the traditional cheeses of Turkey. Although a potential market for traditional cheeses in Turkey, little is known about consumer preferences and attitudes.

Tulum cheese is a popular Turkish cheese variety that is traditionally produced from raw milk, processed and aged in goatskins. Tulum cheese is made from sheep or goat milk or the mixture of these milks. But it can also made from cow milk (Karabiyikli, 2012). With the exception of Thrace, Tulum cheese is produced in every region in Turkey, although the methods and ripening times vary significantly. As a result, it is not always possible to find Tulum cheese of a standard quality. Varieties of Tulum cheese are referred to by the names of the regions where they are traditionally produced and they include Erzincan (Savak), Divle, Cimi and Izmir Tulum (Bayar and Ozrenk, 2011).

Few studies that were carried out to date have analysed consumer preferences with regard to cheese (Bernabéu et al., 2008; Monteiro and Lucas, 2001; Murphy et al., 2004; Tendero and Bernabéu, 2005). A study carried out by 
Bernabéu et al. (2008) indicated that the main differentiating element for cheese was origin in a study carried out in Spain. Monteiro and Lucas (2001) applied conjoint analysis to understand how consumers value in terms of preferences considering four main quality attributes of traditional cheeses: price, quality certification label, type of paste or texture and sale size unit. Monteiro and Lucas (2001) found that the most important attribute for the choice of a Portuguese traditional cheese was its classification as a PDO (protected designation of origin) product. Murphy et al. (2004) stated that the ideal irish farmhouse cheese was one which constituted the following: a strong flavour, a hard texture, a wax packaged wheel, made with pasteurised milk, nutritional information present on the package, a white coloured cheese, a price of $€ 3.17$ per 200 g. Murphy et al. (2004) found that packaging was regarded as the most important attribute followed by flavour, price, colour, nutritional information, pasteurisation and texture. Tendero and Bernabéu (2005) identified consumer preferences for cheeses in Spain. They indicated that consumers value most the DO (destination of origin) labels as a guarantee of a quality and food safety. They also emphasized that consumers prefer cheeeses which are wellpriced, aged and, if possible, certified.

The main objectives of this study are as follows: i) to determine the main attributes that the cheese consumers look for when purchasing Tulum cheese which is one of the traditional cheeses of Turkey; ii) to identify the attributes of an 'ideal' Tulum cheese in the minds of consumers, in terms of which attributes influence choice of product and the respective levels of these attributes; iii) to identify segments of consumers with similar preference profiles according to these attributes and the attributes of an ideal Tulum cheese for each segment. Additionally, this study estimates the Consumers' willingness to pay for regional Tulum Cheese.

\section{Materials and Methods}

In this study, Conjoint Analysis (CA) was used to estimate consumer preference for Tulum cheese. CA has been used in numerous applications involving multiattribute consumer choices. In the food literature, CA has been applied to investigate consumer preferences for different food product attributes and to understand consumer purchase decisions (Michel et al., 2011). Conjoint analysis is multivariate technique specifically used to analyse consumer preferences among a range of products by assessing the utility that consumers attribute to individual product characteristics. Individual consumers utility, which represents the overall preference or total "worth" of a product, can be disaggregated into "part-worths" for each level of the 'important product attributes (Hair et al., 1992).

There are essentially three steps involved in a conjoint study. First, relevant product attributes and their levels must be defined in a manner that is consistent with the buyer's understanding of the product. Second, an experimental design and a survey instrument must be constructed to collect the conjoint data. At this stage, a set of hypothetical products is defined by combining product attributes at various levels. Subjects then are asked to evaluate their overall preference rating or ranking of the hypothetical products. The final step of CA involves choosing an appropriate composition model and estimating the buyer's partworth utilities (Harrison et al., 1998).

\section{Selection of product attributes and determination of the relevant attribute levels}

To implement a conjoint analysis it is necessary to identify all of those attributes that will form part of the study, as well as establishing the levels associated with each attribute (Bernabéu, 2008). By means of interviews with experts, a preliminary questionnaire and a review of literature, the most representative attributes and levels in the Tulum cheese buying process were selected. The attributes (and their levels) identified as most important when buying Tulum cheese were: a) texture (hard, halfhard and soft), b) flavour (strong and mild), c) type of milk used for Tulum cheese making (cow, sheep and mixed cow \&sheep), d) fat (full fat, semi skimmed), e) salinity (salty and low salt), f) origin (regional and non-regional), and g) price (10 TL/kg, $15 \mathrm{TL} / \mathrm{kg}$ and $20 \mathrm{TL} / \mathrm{kg}$ ) (Table 1). Regional level as origin is used to denote Tulum cheese produced in Izmir province of Turkey. Tulum cheese is differentiated in Turkey by location. Cheese originating from different parts of the country differs in taste due to variation in production techniques. Most notable Tulum cheeses are Izmir, Erzincan, Divle, Çimi, and Kargl. The Tulum cheese of Izmir differs from other regional Tulum cheese varieties in processing and characteristics (Anar, 1999).

\section{Experimental design}

In this study, there are four two-level attributes (flavour, fat, salinity, and origin) and three three-level attributes (texture, type of milk, and price). A full profile approach would involve $432(3 \times 2 \times 3 \times 2 \times 2 \times 2 \times 3)$ profiles for the Tulum cheese. To reduce the number of profiles to a manageable size, the orthogonal design procedure in SPSS statistical program was used. This reduced the number of 
Table 1. Attributes and attribute levels of Tulum cheese

\begin{tabular}{cl}
\hline \hline Attribute & \multicolumn{1}{c}{ Levels } \\
\hline \multirow{3}{*}{ Texture } & $\begin{array}{l}\text { (1) hard } \\
\text { (2) half-hard } \\
\text { (3) soft }\end{array}$ \\
\hline \multirow{2}{*}{ Flavour } & $\begin{array}{l}\text { (1) strong } \\
\text { (2) mild }\end{array}$ \\
\hline \multirow{3}{*}{ Type of milk } & (1) cow milk \\
& (2) sheep milk \\
& (3) mixed cow and sheep milk \\
\hline \multirow{2}{*}{ Fat } & (1) full fat cheese \\
& (2) semi-skimmed cheese \\
\hline \multirow{2}{*}{ Salinity } & (1) salty cheese \\
& (2) low salt cheese \\
\hline \multirow{2}{*}{ Origin } & (1) regional \\
& (2) non-regional \\
\hline \multirow{3}{*}{ Price (TL/kg)* } & (1) 10 \\
& (2) 15 \\
& (3) 20
\end{tabular}

*Turkish Lira (TL), the monthly average exchange rate for Turkish Lira vs Euro $(€)$ in December of 2011: 2.45

profiles to be evaluated to 16 .

Having established the card profiles for Tulum cheese, each respondent was given sixteen cards, with each card defining the levels of each of the seven attributes. Respondents were asked to rate each of the sixteen cards by circling the most appropriate number, where one equals a completely unsatisfactory product and ten equals an ideal product (Table 2).

\section{Survey and data collection}

A questionnaire survey was constructed to collect the conjoint data. Izmir was chosen as the city in which to conduct the research. Izmir is located in western Turkey, on the coast of the Aegean Sea and is the third largest city of Turkey with a population of 3,948,848 (as of December 2011). The sample size of the consumers to be questioned is determined considering the number of citizens residing in 11 metropolitan districts in Izmir. In total, there are 2,774,103 citizens in the centre of these metropolitan districts (TurkStat, 2010). Based on the assumption that an average household consists of 4 members, it was calculated that there were a total of 693,526 households in the metropolitan districts of Izmir. The sample size was calculated using the proportional sampling method (Newbold, 1995) :

$$
n=\frac{N p(1-p)}{(N-1) \sigma_{\hat{p}_{x}}^{2}+p(1-p)}
$$

$n$ : Sample size; $N$ : number of households in the metropolitan districts of Izmir; $p$ : The percentage of consumers who purchase Tulum cheese (taken as 0.50 to reach maximum sample size); $\sigma_{\hat{p}_{x}}^{2}$ : variance

According to the proportional sampling method, with a $99 \%$ confidence interval and $9.5 \%$ margin of error, the required sample size was found to be 185 . The sample size (185) was distributed to 11 metropolitan districts in Izmir, according to the ratio of the population in these districts to the total population as follows: Balcova: 5, Bornova: 27, Buca: 28, Cigli: 10, Gaziemir: 9, Guzelbahce: 2, Karsiyaka: 21, Konak: 27, Narlidere: 5, Bayrakli: 20, and Karabaglar: 31 . The survey was conducted face to face with the consumers in front of supermarkets in December 2011. The interviewed consumers were approached ran-

Table 2. Hypothetical Tulum cheese cards presented to respondents

\begin{tabular}{|c|c|c|c|c|c|c|c|}
\hline $\begin{array}{c}\text { Card } \\
\text { number }\end{array}$ & Texture & Flavour & Type of Milk & Fat & Salty & Origin & $\begin{array}{c}\text { Price } \\
(\mathrm{TL} / \mathrm{kg})\end{array}$ \\
\hline 1 & hard & strong & sheep & semi-skimmed & salty & non-regional & 10 \\
\hline 2 & hard & strong & cow & semi-skimmed & low salt & regional & 20 \\
\hline 3 & soft & mild & sheep & full fat & salty & regional & 20 \\
\hline 4 & hard & mild & sheep & semi-skimmed & low salt & regional & 10 \\
\hline 5 & soft & mild & cow & full fat & low salt & non-regional & 10 \\
\hline 6 & hard & strong & cow & full fat & salty & non-regional & 15 \\
\hline 7 & half-hard & strong & mixed cow and sheep & full fat & salty & regional & 10 \\
\hline 8 & half-hard & mild & sheep & semi-skimmed & low salt & non-regional & 15 \\
\hline 9 & soft & strong & mixed cow and sheep & semi-skimmed & low salt & non-regional & 10 \\
\hline 10 & hard & mild & mixed cow and sheep & semi-skimmed & salty & non-regional & 20 \\
\hline 11 & hard & strong & sheep & full fat & low salt & regional & 10 \\
\hline 12 & half-hard & strong & sheep & full fat & low salt & non-regional & 20 \\
\hline 13 & hard & mild & mixed cow and sheep & full fat & low salt & regional & 15 \\
\hline 14 & soft & strong & sheep & semi-skimmed & salty & regional & 15 \\
\hline 15 & half-hard & mild & cow & semi-skimmed & salty & regional & 10 \\
\hline 16 & hard & mild & sheep & full fat & salty & non-regional & 10 \\
\hline
\end{tabular}


domly and these were the respondents who knew and bought Tulum cheese.

\section{Estimation of part-worth utilities}

In conjoint measurement, a customer's total utility for a product is a function of his/her part-worth utilities. In order to determine a customer's total utility for a product, partworth utilities for each product attribute must be estimated (Harrison et al., 1998). The conjoint analysis procedure calculates the contribution of each product attribute to the respondent's preference. The contribution of the attribute level is termed its "part-worth utility" (Murphy et al., 2004). Most CA studies use Ordinary Least Square (OLS) or ordered regression models such as ordered probit and two-limit tobit to measure respondent part worth values (Mclennon, 2002). In this study; for each respondent, the parth-worths were estimated using Ordinary Least Square (OLS) regression analysis. OLS regression assumes independent product attributes.

Given the attributes used in this investigation, the overall preference or total utility of a combination $(P)$ can be expressed by the following model:

$$
\begin{aligned}
P= & \text { Utexture }_{i}+\text { Uflavour }_{j}+\text { Umilk }_{k}+\text { Ufat }_{l}+\text { Usalinity }_{m} \\
& + \text { Uorigin }_{n}+\text { Uprice }_{r}+\text { constant }^{\text {sontal }}
\end{aligned}
$$

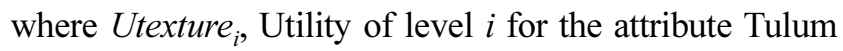
cheese's texture; Uflavour $j$, Utility of level $j$ for the attribute Tulum cheese flavour; Umilk $k_{k}$, Utility of level $k$ for the attribute type of milk used for cheese making; Ufat ${ }_{l}$ Utility of level 1 for the attribute fat content of Tulum cheese; Usalinity $_{m}$, Utility of level $m$ for the attribute salt level in Tulum cheese; Uorigin $n$, Utility of level $n$ for the attribute origin of Tulum cheese; Uprice $r$, Uorigin ${ }_{n}$ Utility of level $r$ for the attribute price of Tulum cheese per kilogram.

For price, a linear relation was established given that, at a higher price, the utility or preference is generally less (Schnettler et al., 2009). Price was assumed to follow a linear-less model since, it typically, showed an inverse relationship with purchase intent (Topcu et al., 2010). The remaining attributes were considered to be discrete variables. Therefore, to estimate partial utility scores, the following econometric model was formulated:

$$
\begin{aligned}
P_{i}= & \beta_{0}+\beta_{1} T_{1}+\beta_{2} T_{2}+\beta_{3} T_{3}+\beta_{4} F V_{1}+\beta_{5} F V_{2}+\beta_{6} M_{1} \\
& +\beta_{7} M_{2}+\beta_{8} M_{3}+\beta_{9} F_{1}+\beta_{10} F_{2}+\beta_{11} S_{1}+\beta_{12} S_{2} \\
& +\beta_{13} R_{1}+\beta_{14} R_{2}+\beta_{15} P_{1}+\beta_{16} P_{2}+\beta_{17} P_{3}+e_{i}
\end{aligned}
$$

where $P_{i}$ represents the utility or preference level for the $i$ th individual, $T_{1}$ is the hard texture cheese variable, $T_{2}$ is the half-hard texture cheese variable, $T_{3}$ is the soft texture cheese variable, $F V_{1}$ is the strong flavored cheese variable, $F V_{2}$ is the mild flavored cheese variable, $M_{1}$ is the cow milk variable used for Tulum cheese making, $M_{2}$ is the sheep milk variable used for Tulum cheese making, $M_{3}$ is the mixed cow and sheep milk variable used for Tulum cheese making, $F_{1}$ is the full fat cheese variable, $F_{2}$ is the semi skimmed cheese variable, $S_{1}$ is the salty cheese variable, $S_{2}$ is the low salt cheese variable, $R_{1}$ is the regional cheese variable which belongs to Izmir region, $R_{2}$ is the non-regional cheese variable which belongs to the different regions of Turkey, $P_{1}$ is price of Tulum cheese 10 TL per kilogram variable, $P_{2}$ is price of Tulum cheese $15 \mathrm{TL}$ per kilogram variable, $P_{3}$ is price of Tulum cheese $20 \mathrm{TL}$ per kilogram variable, $\beta_{0}$ is the regression constant; $\beta_{1}, \beta_{2}, \beta_{3}, \beta_{4}, \beta_{5}, \beta_{6}, \beta_{7}, \beta_{8}, \beta_{9}, \beta_{10}, \beta_{11}$, $\beta_{12,} \beta_{13}, \beta_{14}, \beta_{15}, \beta_{16}$, and $\beta_{17}$ are the partial utility scores associated with the levels of each attribute and $e_{i}$ is the error of estimation.

\section{Measure of the Relative Importance of Product Attributes}

Conjoint also uses the utility ranges to compute importance scores for each attribute (Murphy et al., 2004). The difference between the highest and lowest part-worth establishes the utility range for the attribute. Once a range for each attribute has been determined, the relative importance of its attribute is calculated as follows (Harrison et al., 1998):

$$
R I(\%)=\max U_{i}-\min U_{i} / \Sigma \max U_{i}-\min U_{i}
$$

where, $R I=$ relative importance; $\max U_{i}=$ maximum utility; $\min U_{i}=$ minimum utility.

\section{Determining Consumer Segments}

Conjoint results are very useful for segmentation purposes. The TwoStep Cluster Analysis was chosen to determine consumer segments according to their attribute important scores and socio-demographic variables like gender, age, marital status, educational level, household income, and household size. TwoStep Cluster is an algorithm primarily designed to analyze large datasets. The algorithm groups the observations in clusters, using the approach criterion. The procedure uses an agglomerative hierarchical clustering method. Compared to classical methods of cluster analysis, TwoStep enables both continuous and categorical attributes. Moreover, the method can automatically determine the optimal number of clusters (Schiopu, 2010). The significant differences between the segments were identified using Chi-squared test. 


\section{Validity of the Conjoint Model}

The validity of the conjoint model assessed how well the model fitted the ratings for an individual. Pearson's $\mathrm{R}$ and Kendall's tau association values were used to assess the validity of the conjoint analysis model. The model had a good fit as both the association measures, Pearson's $\mathrm{R}$ and Kendall's tau measures were close to one, which indicated that there was a good agreement between the average card rating and the card utilities predicted by the model (Bogue et al., 2005).

\section{Determining Willingness to Pay for Regional Tulum Cheese}

Based on the results of the conjoint analysis, willingness to pay (WTP) for regional Tulum cheese was calculated. Willingness to pay is represented by implicit prices, showing the maximum amount of money consumers are willing to pay in exchange for a different attribute level for the good. Implicit prices can be determined using the ratio of the price attribute coefficient to the difference of the coefficients of the attribute levels of interest. In this study, the compensating surplus equation was used to estimate the implicit prices as shown in equation (Imami et al., 2011):

$$
C V=-1 / \beta_{m}\left(V^{1}-V^{0}\right)
$$

Where, $\beta_{m}$ is the parameter estimate of price, and $V^{0}$ and $V^{1}$ are the initial utility and the desired utility, respectively.

\section{Results and Discussion}

\section{The socio-economic characteristics of respondents}

Table 3 provides a brief summary of the socio-economic characteristics of the respondents. The respondents were predominantly female (55.14\%) more than male $(44.86 \%)$. The majority of male respondents weremarried $(68.11 \%)$.

From the total sample, $30.81 \%$ is located in the age group of 25-34 years old; meanwhile $25.95 \%$ and $26.49 \%$ are aged between 35-44 and 45-54 years old, respectively. It can be noticed that 25-44 years old group represents more than $50 \%$ of the respondents. On the other hand, $8.64 \%$ is aged above 55 or more years old and only $8.11 \%$ of the sample is aged 24 or less years old. The average age of respondents is 39.02 years old.

The majority of the respondents $(61.08 \%)$ have a bachelor's degree or higher. The persons having primary education represents $14.05 \%$ of the sample, meanwhile $24.87 \%$ of the respondents have secondary education. The respon-
Table 3. Socio-economic characteristics of survey respondents

\begin{tabular}{|c|c|c|c|}
\hline Variable & Level & Frequency & Percent \\
\hline \multirow{2}{*}{ Gender } & Male & 83 & 44.86 \\
\hline & Female & 102 & 55.14 \\
\hline \multirow{7}{*}{ Age } & $18-24$ & 15 & 8.11 \\
\hline & $25-34$ & 57 & 30.81 \\
\hline & $35-44$ & 48 & 25.95 \\
\hline & $45-54$ & 49 & 26.49 \\
\hline & $55-64$ & 15 & 8.10 \\
\hline & 65 and more & 1 & 0.54 \\
\hline & The average age & \multicolumn{2}{|c|}{39.02 (years) } \\
\hline \multirow{2}{*}{$\begin{array}{c}\text { Marital } \\
\text { status }\end{array}$} & Married & 126 & 68.11 \\
\hline & Single & 59 & 31.89 \\
\hline \multirow{4}{*}{$\begin{array}{l}\text { Education } \\
\text { level }\end{array}$} & Primary school & 26 & 14.05 \\
\hline & Secondary school & 46 & 24.87 \\
\hline & Bachelor/post-graduate degree & 113 & 61.08 \\
\hline & The average education level & \multicolumn{2}{|c|}{14.44 (years) } \\
\hline \multirow{5}{*}{$\begin{array}{l}\text { Household } \\
\text { income } \\
\text { (monthly) } \\
\text { (TL) }\end{array}$} & Less than 1000 & 9 & 4.86 \\
\hline & $1000-1499$ & 21 & 11.35 \\
\hline & $1500-1999$ & 30 & 16.22 \\
\hline & $2000-2499$ & 39 & 21.08 \\
\hline & 2500 and more & 86 & 46.49 \\
\hline \multirow{6}{*}{$\begin{array}{l}\text { Household } \\
\text { size }\end{array}$} & 1 person & 8 & 4.32 \\
\hline & 2 people & 30 & 16.22 \\
\hline & 3 people & 70 & 37.84 \\
\hline & 4 people & 57 & 30.81 \\
\hline & 5 people and more & 20 & 10.81 \\
\hline & The average household size & \multicolumn{2}{|c|}{3.32 (persons) } \\
\hline
\end{tabular}

dents had an average of 14.44 years of education.

The monthly average household income of respondents has been divided into five categories. Income levels of respondents are quite variable ranging from lower income levels (less than 1,000 TL) to upper income levels (more than 2,500 TL). The majority (46.49\%) of the respondents are categorized in the upper income levels $(2,500 \mathrm{TL}$ and more); meanwhile $21.08 \%$ and $16.22 \%$ of the respondents belong to the 2,000-2,499 segment and 1,500-1,999 segment, respectively. The proportion of respondents in the lowest income group is quite low (4.86\%).

Regarding household size, almost $38 \%$ of the respondents pointed out that the number of persons living in the household is 3 . On the other hand, $30.81 \%$ said that the number of persons living in the household is 4 . Only $4.32 \%$ of the sample pointed out that they live alone. The average household size of the respondents was 3.32 persons per household.

\section{Part-worth and relative importance of attributes}

Table 4 shows the part-worth utility scores for each level of each attribute. Type of milk used for Tulum cheese mak- 
ing was identified as the most important factor $(28.82 \%)$, followed by Tulum cheese's texture (16.19\%), price (14.82\%), salinity $(13.58 \%)$, fat content of Tulum cheese $(9.54 \%)$, origin $(8.69 \%)$ and flavour $(8.37 \%)$.

Within the attributes, the utilities of each level were also investigated. The overall 185 respondents obtained a higher utility from a Tulum cheese made with cow milk $(\mathrm{U}=0.5901)$ than from a cheese made with sheep milk ( $\mathrm{U}=$ $-0,1234)$ and mixed cow and sheep milk ( $U=-0,4667)$.

Within texture, the most utility was obtained from hard texture cheese $(\mathrm{U}=0.1180)$, whereas the utility of a halfhard texture cheese was lower $(\mathrm{U}=0.0153)$, but higher than a soft texture cheese $(\mathrm{U}=-0.1333)$.

Within price, a price of $20 \mathrm{TL}$ per $\mathrm{kg}$ had the highest utility ( $\mathrm{U}=0.5108$ ) among the price levels, compared to a price of $15 \mathrm{TL}(\mathrm{U}=0.3405)$ and $10 \mathrm{TL}(\mathrm{U}=0.1703)$. This shows that the respondents were not sensitive to price. This result is similar to results obtained from previous studies (Cowan et al., 2000; Murphy et al., 2004; Tendero and Bernabéu, 2005). These studies show that consumers were not price conscious, deriving a higher utility from cheese that was of a higher price.
Fourth important factor affecting purchase decision of respondents for Tulum cheese was salt level in Tulum cheese with $13.58 \%$ relative importance. Within salinity, the most utility was obtained from Tulum cheese made with the lower salt content ( $U=0.3628)$, whereas the utility of a salty Tulum cheese was lower $(\mathrm{U}=-0.3628)$.

Fat content of Tulum cheese was preferred as fifth factor with $9.54 \%$ relative importance. The respondents obtained a higher utility from a full-fat Tulum cheese $(\mathrm{U}=0.0689)$, than from a semi-skimmed Tulum cheese ( $U=-0.0689)$.

On the other hand, origin and flavour were preferred as sixth and seventh factors with $8.69 \%-8.37 \%$ relative importance, respectively. When the origin of the Tulum cheese was considered, the regional cheese which belongs to Izmir region was preferred the most with a utility value of 0.1250 , compared to Tulum cheeses produced in different regions in Turkey except for the Izmir region.

The utility value of mild-flavoured Tulum cheese ( $\mathrm{U}=$ 0.0649) was higher in comparison with the strong-flavoured Tulum cheese $(\mathrm{U}=-0.0649)$. This means that respondents preferred a mild-flavoured Tulum cheese.

The conjoint analysis for the overall 185 consumers found

Table 4. Part-worths and relative importance of attributes

\begin{tabular}{|c|c|c|c|c|c|c|c|}
\hline \multirow[b]{2}{*}{ Attribute } & \multirow[b]{2}{*}{ Level } & \multicolumn{2}{|c|}{ All consumers $(\mathrm{n}=185)$} & \multicolumn{2}{|c|}{ Cluster $1(n=59)$} & \multicolumn{2}{|c|}{ Cluster $2(\mathrm{n}=126)$} \\
\hline & & Utility & $\begin{array}{c}\text { Relative } \\
\text { importance }(\%) \\
\end{array}$ & Utility & $\begin{array}{c}\text { Relative } \\
\text { importance (\%) }\end{array}$ & Utility & $\begin{array}{c}\text { Relative } \\
\text { importance (\%) }\end{array}$ \\
\hline \multirow{3}{*}{ Texture } & hard & 0.1180 & \multirow{3}{*}{16.19} & -0.0254 & \multirow{3}{*}{17.72} & 0.1852 & \multirow{3}{*}{15.47} \\
\hline & half-hard & 0.0153 & & -0.0021 & & 0.0235 & \\
\hline & soft & -0.1333 & & 0.0275 & & -0.2087 & \\
\hline \multirow{2}{*}{ Flavour } & strong & -0.0649 & \multirow{2}{*}{8.37} & -0.1102 & \multirow{2}{*}{10.53} & -0.0437 & \multirow{2}{*}{7.37} \\
\hline & mild & 0.0649 & & 0.1102 & & 0.0437 & \\
\hline \multirow{3}{*}{ Type of milk } & cow milk & 0.5901 & \multirow{3}{*}{28.82} & 0.7210 & \multirow{3}{*}{31.35} & 0.5288 & \multirow{3}{*}{27.63} \\
\hline & sheep milk & -0.1234 & & -0.2684 & & -0.0556 & \\
\hline & mixed cow and sheep milk & -0.4667 & & -0.4527 & & -0.4732 & \\
\hline \multirow{2}{*}{ Fat } & full fat cheese & 0.0689 & \multirow{2}{*}{9.54} & 0.0381 & \multirow{2}{*}{8.78} & 0.0833 & \multirow{2}{*}{9.89} \\
\hline & semi-skimmed cheese & -0.0689 & & -0.0381 & & -0.0833 & \\
\hline \multirow{2}{*}{ Salinity } & salty cheese & -0.3628 & \multirow{2}{*}{13.58} & -0.2521 & \multirow{2}{*}{11.21} & -0.4147 & \multirow{2}{*}{14.69} \\
\hline & low salt cheese & 0.3628 & & 0.2521 & & 0.4147 & \\
\hline \multirow{2}{*}{ Origin } & regional & 0.1250 & \multirow{2}{*}{8.69} & 0.0085 & \multirow{2}{*}{8.04} & 0.1796 & \multirow{2}{*}{8.99} \\
\hline & non-regional & -0.1250 & & -0.0085 & & -0.1796 & \\
\hline \multirow{4}{*}{$\begin{array}{c}\text { Price } \\
\text { (TL/kg) }\end{array}$} & 10 & 0.1703 & \multirow{3}{*}{14.82} & -0.1248 & \multirow{3}{*}{12.39} & 0.3084 & \multirow{3}{*}{15.96} \\
\hline & 15 & 0.3405 & & -0.2496 & & 0.6169 & \\
\hline & 20 & 0.5108 & & -0.3744 & & 0.9253 & \\
\hline & Constant & 4.6797 & & 5.2961 & & 4.3911 & \\
\hline & Corre & ions betwe & n observed and es & nated pre & rences & & \\
\hline & & Value & Sig.* & Value & Sig.* & Value & Sig.* \\
\hline & arson's R & 0.977 & 0.000 & 0.945 & 0.000 & 0.983 & 0.000 \\
\hline & ndall's tau & 0.862 & 0.000 & 0.790 & 0.000 & 0.900 & 0.000 \\
\hline
\end{tabular}

*The Pearson and Kendall tau coefficients of correlation were significant at the 99 percent confidence level. 
that the ideal Tulum cheese had the following attributes: made with cow milk, a hard texture, a price of $20 \mathrm{TL}$ per $\mathrm{kg}$, a low salt cheese, a full fat cheese and the regional cheese which belongs to Izmir region and a mild-flavoured cheese.

The result of this study also shows that respondents' total utility derived from part-utility values of each attribute level by taking into account of the attributes of an ideal Tulum cheese. The combination, which has the highest total worth is defined as the product feature set providing the consumers with optimum utility. The factor and factor level having the highest total utility is preferred by consumers with priority (Akpinar et al., 2009). The total utility is calculated using the equation below:

$$
\begin{aligned}
\text { Total P }= & \text { Utexture }_{i}+\text { Uflavour }_{j}+\text { Umilk }_{k}+\text { Ufat }_{l} \\
& + \text { Usalinity }_{m}+\text { Uorigin }_{n}+\text { Uprice }_{r}+\text { constant } \\
\text { Total P }= & 0.1180+0.0649+0.5901+0.0689+0.3628 \\
& +0.1250+0.5108+4.6797=6.5202
\end{aligned}
$$

As calculated, the ideal Tulum cheese profiles, which provides the consumers with optimum benefit, maximized consumers' total utility with 6.5202 total value.

Pearson's R and Kendall's tau association values were used to assess the validity of the conjoint analysis model. The model had a good fit as both the association measures, Pearson's R (0.977) and Kendall's tau (0.862) measures were close to one, it is also significant at a 99 percent level.

\section{Consumer Segments}

As mentioned earlier, a cluster analysis was used to help identify consumer segments based on respondents' preferences and socio-demographic characteristics. The cluster analysis revealed two clusters within the sample of 185 subjects. The first cluster contained 59 respondents and the second contained 126 . The results by segments are presented in Table 4.

Cluster 1's ideal Tulum cheese comprised a soft texture, a mild-flavoured cheese, a cheese made with cow milk, a full fat cheese, a low salt cheese and the regional cheese which belongs to Izmir region and a price of $10 \mathrm{TL}$ per $\mathrm{kg}$. Type of milk used for Tulum cheese was the most important attribute for this segment of consumers. Cluster 1 derived the highest positive utility from a Tulum cheese made with cow milk ( $\mathrm{U}=0.7210)$. Fat content of Tulum cheese $(8.78 \%)$ and origin $(8.04 \%)$ were considered the least important attributes for cluster 1 . Price $(12.39 \%)$ is the third most important factor affecting purchase decision of the consumers in cluster 1 for Tulum cheese. Within price, $10 \mathrm{TL}$ per $\mathrm{kg}$ was considered to have the highest utility, followed by $15 \mathrm{TL}$ and then $20 \mathrm{TL}$. This shows that consumers in cluster 1 were sensitive to price.

Cluster 2 differed from cluster 1 in that its ideal Tulum cheese was a hard textured cheese and priced at $20 \mathrm{TL}$ per kg. Type of milk used for producing the Tulum cheese was again the most important attribute, followed by price, texture, salinity, fat content, origin and flavour. The consumers in cluster 2 attached a higher importance to the for price, salinity, fat content and origin than consumers in cluster 1 . Cluster 2 had the highest utility for a price of $20 \mathrm{TL}$ per $\mathrm{kg}$. The consumers in cluster 2 were therefore less price sensitive than those in cluster 1 and the overall 185 consumers.

To determine whether consumers in the two segments differed by socioeconomic characteristics, we calculated chi-square statistics based on the distribution of consumers with various socioeconomic characteristics. Table 5 shows the socioeconomic profile for each cluster. Each cluster is broken down in terms of gender, age group, marital status, educational level, household net income and household size.

Chi square test results revealed that there were statistically significant difference between the two segments at different probability levels with regard to gender, age group, marital status, educational level, and household size. No significant difference in average monthly household income was observed between the two segments $(p>0.01)$.

Cluster 1 contained consumers of which the majority were female, young, single and well-educated. Cluster 1 consumers had medium range disposable incomes, but had smaller household size.

Cluster 2 contained almost equal numbers of female and male consumers of which the majority were married. Generally, this cluster was older and less well-educated than members of the other cluster. Cluster two consumers had high range disposable incomes. The average household size in cluster 2 was higher than the other cluster.

\section{Consumers' willingness to pay for regional Tulum Cheese}

As previously discussed, origin of the Tulum cheese is very important for two consumer segments. When the origin of the Tulum cheese was considered, the regional cheese which belongs to Izmir region was preferred the most, compared to Tulum cheeses produced in different regions in Turkey except for the Izmir region.

The consumers in cluster 1 are willing to pay $0.14 \mathrm{TL}$ for each $\mathrm{kg}$ of regional Tulum cheese as compared to nonregional Tulum cheeses $((0.0085-(-0.0085)) /(-0.1248)$. 
Table 5. Demographic profile for clusters

\begin{tabular}{|c|c|c|c|c|c|}
\hline Variable & Level & Cluster $1(\%)$ & Cluster $2(\%)$ & Chi-square & p-value \\
\hline \multirow{2}{*}{ Gender } & Male & 32.20 & 50.79 & \multirow{2}{*}{5.614} & \multirow{2}{*}{$0.018^{* *}$} \\
\hline & Female & 67.80 & 49.21 & & \\
\hline \multirow{6}{*}{ Age } & $18-24$ & 25.42 & 0.00 & \multirow{6}{*}{71.206} & \multirow{6}{*}{$0.000^{*}$} \\
\hline & $25-34$ & 54.24 & 19.84 & & \\
\hline & $35-44$ & 8.47 & 34.13 & & \\
\hline & $45-54$ & 10.17 & 34.13 & & \\
\hline & 55 and more & 1.69 & 11.90 & & \\
\hline & The average age & 30.12 & 43.18 & & \\
\hline \multirow{2}{*}{ Marital status } & Married & 3.39 & 98.41 & \multirow{2}{*}{167.043} & \multirow{2}{*}{$0.000^{*}$} \\
\hline & Single & 96.61 & 1.59 & & \\
\hline \multirow{4}{*}{ Education level } & Primary school & 5.08 & 18.25 & \multirow{4}{*}{8.255} & \multirow{4}{*}{$0.016^{* *}$} \\
\hline & Secondary school & 20.34 & 26.98 & & \\
\hline & Graduate/professional degree & 74.58 & 54.76 & & \\
\hline & The average education level & 15.68 & 13.87 & & \\
\hline \multirow{5}{*}{$\begin{array}{l}\text { Household income } \\
\text { (monthly) (TL) }\end{array}$} & Less than 1000 & 5.08 & 4.76 & \multirow{5}{*}{6.420} & \multirow{5}{*}{0.170} \\
\hline & $1000-1499$ & 15.25 & 9.52 & & \\
\hline & 1500-1999 & 23.73 & 12.70 & & \\
\hline & $2000-2499$ & 20.34 & 21.43 & & \\
\hline & 2500 and more & 35.59 & 51.59 & & \\
\hline \multirow{6}{*}{ Household size } & 1 person & 13.56 & 0.00 & \multirow{6}{*}{29.315} & \multirow{6}{*}{$0.000 *$} \\
\hline & 2 people & 22.03 & 13.49 & & \\
\hline & 3 people & 25.42 & 43.65 & & \\
\hline & 4 people & 23.73 & 34.13 & & \\
\hline & 5 people and more & 15.25 & 8.73 & & \\
\hline & The average household size & 3.17 & 3.40 & & \\
\hline
\end{tabular}

*Significant at 0.01 level, ${ }^{* * \text { Significant at } 0.05 \text { level }}$

These result indicates that the consumers in cluster 1 would be willing to pay approximately $0.14 \mathrm{TL}$ more for a kilogram of regional Tulum cheese. The consumers in cluster 2 seem to appreciate very much regional Tulum cheese, since they are ready to pay an additional $1.16 \mathrm{TL}$ per $\mathrm{kg}$ of regional Tulum cheese versus non-regional Tulum cheese.

\section{Conclusions}

In this study we have reported the results of a research aimed at detecting which factors mostly affect consumers' preferences for Tulum cheese, which is one of the most important types of Turkish traditionally cheeses. We also determined the ideal combination of attributes of Tulum cheese for different consumer segments.

Within the given range of attributes type of milk used for Tulum cheese making is by far the most important factor for both consumer segments when choosing to buy Tulum cheese. The consumers in cluster 1 attached a higher importance to the type of milk used for Tulum cheese making, cheese's texture and flavour compared with the cluster 2. On the other hand, the consumers in cluster 2 attached a higher importance to the price, salinity, fat content and origin than consumers in cluster 1 .

Cluster 1's ideal Tulum cheese comprised a soft texture, a mild-flavoured cheese, a cheese made with cow milk, a full fat cheese, a low salt cheese, the regional cheese which belongs to Izmir region and a price of $10 \mathrm{TL}$ per kg. Cluster 2 differed from cluster 1 in that its ideal Tulum cheese was a hard textured cheese and priced at $20 \mathrm{TL}$ per $\mathrm{kg}$. The consumers in cluster 2 were less price sensitive than those in cluster 1.

Although the consumers in both segments attached a low relative importance $(8.04 \%-8.99 \%)$ to origin, the regional Tulum cheese which belongs to Izmir region was preferred the most with a higher utility value, compared to Tulum cheeses produced in different regions in Turkey, except for the Izmir region. In addition to, the consumers in both segments are ready to pay extra money for regional Tulum cheese versus non-regional Tulum cheese. We found that the older ones were more willing to pay as compared to younger individuals.

Our results indicate that there were substantial differ- 
ences between consumer segments in terms of demographic characteristics. Thus, market segments according to demographic characteristics can be a useful tool to develop different marketing strategies for each segment.

Izmir has a young population with 52 percent of its people under age 35, 29 percent between age 35 and 54, and 19 percent over 54 years old (TurkStat, 2011). For this reason, young people are a critical target market for Tulum cheese marketers. The findings on cluster 1's ideal Tulum cheese of this study could therefore provide guidance to marketing managers. In the meantime, the results gained from this study will also be as guidance for the investments towards animal husbandry by the farmers. Preference of cow milk by the consumers in cheese production will encourage the investments mostly towards dairy farm in the region. Considering the results of this study, researches which determine the consumer preferences will increase the consumption of traditional foods as cheese and also the number of the producers who will enter the sector.

\section{References}

1. Akpinar, M.G., Dagistan, E., Mazlum, Y., Gul, M., Koc, B., and Yilmaz, Y. (2009) Determining household preferences for fish consumption with conjoint analysis in Turkey. $J$. Anim. Vet. Adv. 8, 2215-2222.

2. Albayrak, M. and Gunes, E. (2010) Traditional foods: Interaction between local and global foods in Turkey. Afr. J. Bus. Manag. 4, 555-561.

3. Anar, Ş. (1999) "Traditional cheeses producing in Turkey" (in Turkish). J. Turkish Food Available from: http://en.wikipedia. org/wiki/Tulum_(cheese). Accessed April 20, 2012.

4. Anonymous. (2007) European research on traditional foods. Official Publications of the European Communities. ISBN 92-79-03315-8, Luxembourg, p. 40.

5. Bayar, N. and Ozrenk, E. (2011) The Effect of quality properties on Tulum cheese using different package materials. Afri. J. Biotechnol. 10, 1393-1399.

6. Bernabéu, R., Olmeda, M., Díaz, M., and Olivas, R. (2008) Determination of the surcharge that consumers are willing to pay for an organic cheese in Spain 12th Congress of the European Association of Agricultural Economists, pp. 1-5.

7. Bogue, J., Hofler, A., and Sorenson, D. (2005) Conjoint analysis as a market-oriented new product design tool: the case of functional meal replacement beverages, Department of Food Business and Development University College, Cork, Agribusiness Discussion, Paper No. 45, p. 38.

8. Cowan, C., Murphy, M., Daly, E., Meehan, H., Henchion, M., Pitts, E., Delahunty, C., and O'Reilly, S. (2000) Consumer attributes of farmhouse cheese and honey, a research within the Framework of the EU-FAIR Programme, Project FAIRCT95-0360, ISBN 1-84170-158-0, Dublin, p. 15.

9. Hair, J., Anderson, R. E., Tatham, R. L., and Black, W. C. (1992) Multivariate data analysis with reading, 3rd ed., Maxwell Macmillan Publishing, Singapore.

10. Harrison, R. W., Ozayan, A., and Meyers, S. P. (1998) A conjoint analysis of new food products processed from underutilized small crawfish. J. Agr. Appl. Econ. 30, 257-265.

11. Imami, D., Chan-Halbrendt, C., Zhang, Q., and Zhllima, E. (2011) Conjoint analysis of consumer preferences for lamb meat in central and southwest urban Albania. Int. Food Agr. Manag. Rev. 14, 111-122.

12. Karabiyikli, Ş. (2012) Some traditional cheeses produced in Turkey, a presentation on cheese, Gaziosmanpasa University. Available from: http://ipff2012.gop.edu.tr/teaching/Turkey/p11.pdf Accessed April 15,2012.

13. Mclennon, E. A. (2002) Analysis of consumer perceptions toward biotechnology and their preferences for biotech food labels, MSc Thesis, B. S. Louisiana State University, The Department of Agricultural Economics and Agribusiness, p. 87.

14. Michel, L. M., Anders, S., and Wismer, W. V. (2011) Consumer preferences and willingness to pay for value-added chicken product attributes. J. Food Sci. 76, 469-477.

15. Monteiro, D. M. S. and Lucas, M. R. V. (2001) Conjoint measurement of preferences for traditional cheeses in Lisbon. Brit. Food J. 103, 414-424.

16. Murphy, M., Cowan, C., and Meehan, H. (2004) A conjoint analysis of Irish consumer preferences for farmhouse cheese. Brit. Food J. 106, 288-300.

17. Newbold P. (1995) Statistics for business and economics, Prentice Hall International Editions.

18. Schiopu, D. (2010) Applying two-step cluster analysis for identifying bank customers' profile, Buletinul, UniversitãÑii Petrol - Gaze din Ploiesti, StiinÑe Economice, Vol. LXII, pp. 66-75.

19. Schnettler, B., Vidal, R., Silva, R., Vallejos, L., and Sepúlveda, N. (2009) Consumer willingness to pay for beef meat in a developing country: The effect of information regarding country of origin, price and animal handling prior to slaughter. Food Qual. Prefer. 20, 156-165.

20. Tendero, A. and Bernabéu, R. (2005) Preference structure for cheese consumers: a Spanish case study. Brit. Food J. 107, 60-73.

21. Topcu, Y., Uzundumlu, A.S., and Yavuz, F. (2010) Designing the marketing strategies for Ispir sugar bean as a local product using conjoint analysis. Sci. Res. Essays 5, 887-896.

22. TurkStat (2010) Address based population registration system (ABPRS): results for Izmir, Turkish Statistical Institute. Available from: http://tuikapp.tuik.gov.tr/adnksdagitapp/adnks. zul?dil=2. Accessed April 18,2012.

23. TurkStat. (2011) Population statistics for Izmir, Turkish Statistical Institute. Available from: http://www.turkstat.gov.tr/ VeriBilgi.do?tb_id=39\&ust_id=11. Accessed April 18,2012.

(Received 2012.6.8/Revised 2012.7.24/Accepted 2012.8.23) 